\title{
Paying wisely for conservation
}

\author{
Giving economic compensation in exchange for securing ecosystem services has gained traction in recent decades. \\ However, debates about the efficacy and ethics of payments abound. To help ensure the effectiveness of these \\ schemes, more care is needed in monitoring environmental outcomes and penalising non-compliance.
}

$\mathrm{P}$ ayments for ecosystem (or environmental) services (PES) are monetary incentives offered to ensure that specific services we value from ecosystems are maintained. For example, downstream water users might pay upstream landowners to protect a stream and its banks, ensuring water provision and quality. As policy instruments, PES schemes can scale from local to global, for example asking the international community to pay for not extracting oil beneath the Amazon to avoid carbon emissions and biodiversity loss. To secure the provision of water, maintain biodiversity or keep carbon stored, those who use the natural assets providing these services have to forego economic gains. Such gains would otherwise sustain their livelihoods and the development of their families. Therefore compensating landowners, farmers and others for a wiser use of natural assets seems like a sensible solution to conserve nature.

Such payments have become a popular policy tool, with at least 550 programmes inventoried across the world, as shown in the article by Salzman and colleagues published in this issue. The authors have analysed a major online database on PES, Ecosystem Marketplace, and found that these schemes, led by both private and government organizations, add up to estimated annual payments of over US\$ 36 billion.

Research on the topic also blossomed in the last few decades. A search in Scopus for studies on PES since 2011 suggests that over 100 new scientific publications annually have assessed PES, tackling big fundamental questions such as how well they work in the real world. The line between any payment scheme and a PES scheme is blurry, which makes understanding the effectiveness of PES trickier still. Often, schemes labelled as PES resemble a subsidy or do not attain theoretically fundamental characteristics for a payment to qualify as PES, such as the need for low transaction costs. In another study in this issue, Wunder and colleagues have analysed a curated database of thoroughly documented PES schemes, and suggest that the economic principles necessary for behavioural change through PES often do not materialize in practice. These principles include the capacity to organize a market, and clear and enforceable property rights. When putting PES into practice, more effort is needed in the key areas of monitoring outcomes and penalizing non-compliance.

\section{We need to know more about how PES compare with other instruments.}

Scholars heatedly debate whether paying people to conserve nature is effective, efficient or ethical. This lack of agreement calls for further, robust evidence for PES schemes to be usefully implemented. A major concern among scholars and practitioners alike is whether paying people to conserve moves their perception of nature from inherently valuable to something that can be monetized (S. Bowles Science 320, $1605-1609 ; 2008)$. One concern is that such a shift in perspective could prompt someone paid to leave a forest uncut to demand continued or rising payments to preserve it indefinitely. This could happen even if the forest owner acted like a steward beforehand. In other words, intrinsic motivations for conservation - those unrelated to economic gains - could be crowded out. Studying such longterm behavioural effects is particularly challenging. A framed-field experiment of unprecedented scale by Andersson and colleagues, also in this issue, suggests that PES schemes encourage sustainable management of common-pool resources, such as a shared forest, not only while payments are offered but also after payments stop. However, the authors also find that facilitating communication among users about the management of the natural resource boosts such long-term pro-environmental behaviour.
We at Nature Sustainability are happy to track progress about PES debates and are conscious that more is needed to better understand the usefulness of these instruments. Under which circumstances might PES work? When could they be counterproductive? In particular, we need to know more about how PES compare with other instruments regarding effectiveness, efficiency or desirability to achieve the same outcome. Other ongoing concerns include how PES schemes might affect local social and cultural interactions and institutions, such as norms about resource use, and what the impacts of expanding markets and trade in newly commodified ecosystem services are likely to be. We welcome critical perspectives on these important topics.

Payment schemes have been in the tool-set of sustainability researchers and practitioners for a while. As one type of economic instrument, PES go alongside others such as taxes and tradable permits. Economic instruments are, in turn, broad categories akin to liability rules; commandand-control regulatory instruments, such as rules and standards; and voluntary measures. In contrast to these other instruments, PES are, in theory, loosely regulated to allow the market to work and should make economic sense to all parties. Making economic sense means that transactions occur only as long as they are economically satisfactory for all trading parties, regardless of other motivations to behave in an environmentally friendly way.

Although popular, PES are one of many instruments available to achieve the sustainable management of natural resources. Given the diversity of contexts and problems to address in sustainability and that no single solution fits all, it is important to consider the whole range of possibilities when deciding how to address each issue.

Published online: 12 March 2018 https://doi.org/10.1038/s41893-018-0044-X 